\title{
Indices and scores, or how to simplify complexity
}

\author{
Martin Czerny, MD, MBA, and Nikolaus Jander, MD
}

\author{
From the University Heart Center Freiburg-Bad Krozingen, Germany. \\ Disclosures: Authors have nothing to disclose with regard to commercial support. \\ Received for publication Feb 6, 2017; accepted for publication Feb 15, 2017; available ahead of print March 21, \\ 2017. \\ Address for reprints: Martin Czerny, MD, MBA, University Heart Center Freiburg-Bad Krozingen, Südring 15 \\ 79189, Germany (E-mail: martin.czerny@universitaets-herzzentrum.de). \\ J Thorac Cardiovasc Surg 2017;153:1285-6 \\ $0022-5223 / \$ 36.00$ \\ Copyright (C 2017 by The American Association for Thoracic Surgery \\ http://dx.doi.org/10.1016/j.jtcvs.2017.02.033
}

Anticipation of adverse events by the planned procedure itself or by additional accompanying risk factors is paramount before any kind of cardiovascular procedure, be it surgical or interventional. At best, the addressed underlying pathology and its consequences are cured after a successful procedure.

Risk factors and their harmonization with risk scores add an additional tool to anticipate immediate risk in classic heart surgery, and several attempts are under way to establish risk scores in cardiovascular interventions. ${ }^{2,3}$ However, few tools are available to anticipate the long-term remaining risk after successful accomplishment of an operation or intervention despite its optimal procedural accomplishment. Mosqueira and colleagues ${ }^{1}$ have elegantly shown that despite the successful procedural accomplishment of surgical aortic valve replacement, the net benefit of the therapy is limited in patients showing large indexed left atrial diameters at the time of surgical aortic valve replacement.

The impact of an enlarged left atrium on survival has been established in various underlying cardiovascular pathologies and now in patients with aortic valve disease undergoing surgery; in aortic stenosis, early diastolic dysfunction due to left ventricular hypertrophy is causative, and in aortic regurgitation, late systolic dysfunction is the reason. This is the component that is simple to understand. The complex component is the interplay of all of the other components involved in the disease process. The crucial question is whether left atrial size enlargement is at the beginning of the process of calcific degeneration or regurgitation develops while calcific degeneration or regurgitation progression is at the end of the process as a consequence of long-standing hemodynamically relevant aortic stenosis or regurgitation or the left atrium enlarges irrespective of the presence or absence of aortic valve pathology. The scenario reminds one of the presence or absence of reduced systolic left ventricular function, which remains one of the strongest predictors of outcome after all types of cardiovascular operations or interventions.

Regardless, adding such parameters to the armamentarium is helpful because they broaden the way of thinking, and it might make the difference between recommending treatment at an earlier time point or remaining with watchful

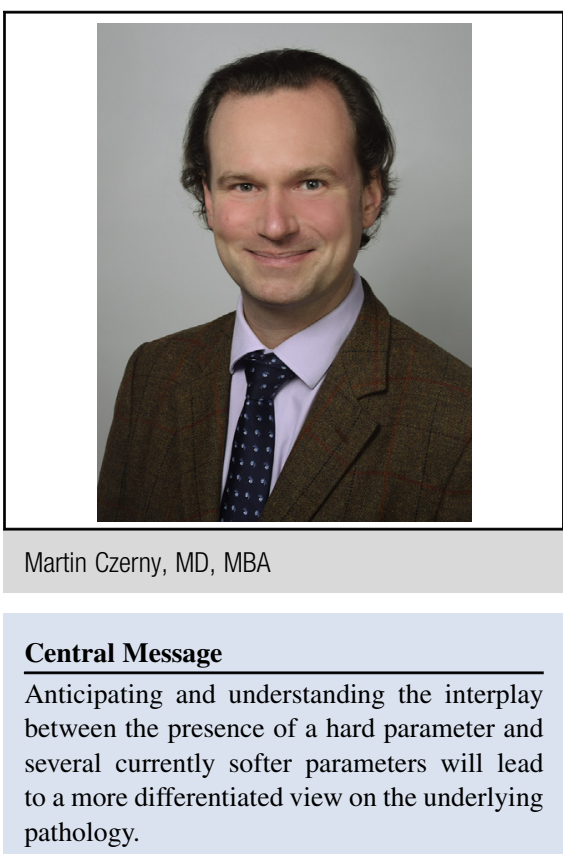

See Article page 1275 .

waiting, for example, implementation of the velocity ratio changed the way of treating patients with low-gradient severe aortic stenosis and preserved ejection fraction. ${ }^{4}$

Another example comes from aortic medicine. Indication of ascending aortic replacement adheres to clear recommendations with regard to the maximum ascending aortic diameter. However, we do know that the majority of patients with an acute type A aortic dissection will have regular aortic diameters at the time of dissection. ${ }^{5}$ Increased aortic length from the sinotubular junction to the offspring of the brachiocephalic trunk recently was identified to be associated with an increased occurrence of ascending aortic dissection. ${ }^{6}$ Therefore, should we operate on all patients with increased aortic length and regular transverse diameters to prevent type A aortic dissection without a known number needed to treat to do good? Most likely not, but knowing about this component might affect our decision making in patients with borderline transverse diameters to recommend treatment at an earlier time point.

Likewise, the findings of the authors have the potential to stimulate future research in patients with newly diagnosed aortic valve pathology by implementing indexed left atrial diameters into the decision-making process of when to recommend treatment irrespective of the presence or absence of symptoms. 
Adding this new component to the armamentarium of anticipating and understanding the interplay between the presence of a hard parameter, such as hemodynamically relevant aortic stenosis or regurgitation, and several currently softer parameters, such as indexed left atrial diameters, will lead to a more differentiated view on the underlying pathology and to a potentially more differentiated view of indicating treatment.

\section{References}

1. Mosqueira VX, Bouzas-Mosquera A, González-Barbeito M, BautistaHernandez V, Muñiz V, Alvarez-García N, et al. Indexed left atrial size predicts all-cause and cardiovascular mortality in patients undergoing aortic valve surgery J Thorac Cardiovasc Surg. 2017;153:1275-84.e7.

2. Nashef SA, Roques F, Sharples LD, Nilsson J, Smith C, Goldstone AR, et al. EuroSCORE II. Eur J Cardiothorac Surg. 2012;41:734-44.

3. O'Brien SM, Shahian DM, Filardo G, Ferraris VA, Haan CK, Rich JB, et al. The Society of Thoracic Surgeons 2008 cardiac surgery risk models: part 2-isolated valve surgery. Ann Thorac Surg. 2009;88:S23-42.

4. Jander N, Hochholzer W, Kaufmann BA, Bahlmann E, Gerdts E, Boman K, et al. Velocity ratio predicts outcomes in patients with low gradient severe aortic stenosis and preserved EF. Heart. 2014;100:1946-53.

5. Rylski B, Blanke P, Beyersdorf F, Desai N, Milewski RK, Siepe M, et al. How does the ascending aortic geometry change when it dissects? J Am Coll Cardiol. 2014; 63:1311-9.

6. Krüger T, Forkavets O, Veseli K, Lausberg H, Vöhringer L, Schneider W, et al. Ascending aorta elongation and the risk of dissection. Eur J Cardiothorac Surg. 2016;50:241-7. 